\title{
Introduction to the special issue 'Integrated scenario building in energy transition research'
}

\author{
Witold-Roger Poganietz ${ }^{1} \cdot$ Wolfgang Weimer-Jehle $^{2}$
}

Published online: 29 September 2020

(C) The Author(s) 2020

\section{Introduction/motivation}

The anthropogenically induced climate change is a core geopolitical challenge in the twentyfirst century, which will be decisive for the long-term global cohabitation of humans, and economic opportunities as a base for wellbeing (WBGU 2011). The energy sector is responsible for 60-70\% of global greenhouse gases (IEA 2015), which sets the transformation of the energy system at the centre of any discussion on how to de-fossilize economic systems and thus minimize the carbon footprint of societies. As climate change is a global challenge, the same is true for changing the way energy systems function.

Ways and means to decarbonize the energy supply are the topic of a broad range of discussions at the highest political levels and are also the topic of uncountable scientific articles. Common to most political or scientific contributions is the use of or reference to scenarios (e.g. IEA 2019). Scenarios show development options by revealing important interdependencies and their relevance. However, scenarios do not predict the future, which is often ignored in discussions. Instead, model-based econometric or techno-economic scenarios make an important contribution to science-based policy advice by pointing out alternative futures and their implications. Since past and current political as well as societal developments reveal that the shape of an energy system and its contribution to greenhouse gas emissions are the outcome of multidimensional interactions within civil society, as well as between civil society, politics, technology, and the economy (Geels 2004; Verbong and Loorbach 2012), meaningful transition scenarios require a sound consideration of the interplay between society, technology, and environment.

This article is part of a Special Issue on 'Integrated Scenario Building in Energy Transition Research' edited by Witold-Roger Poganietz and Wolfgang Weimer-Jehle.

Witold-Roger Poganietz

poganietz@kit.edu

$1 \quad$ Institute for Technology Assessment and Systems Analysis (ITAS), Karlsruhe Institute of Technology (KIT), Karlsruhe, Germany

2 Center for Interdisciplinary Risk and Innovation Studies (ZIRIUS), University of Stuttgart, Stuttgart, Germany 
The German energy transition process is an informative case. It reveals the necessity to consider not only techno-economic constraints but also societal ones. Taking into account the history of the German transition process, the societal dimension, and the relevance of interactions between policy, civil society, economy, and technology is clear. Although nowadays motivated by climate protection considerations, the citizens' movements against nuclear power, which gained prominence from the 1970s, have been identified as one historical but important impetus of the current transition efforts of the energy system (Morris and Pehnt 2012). The design of the German supportive scheme to promote renewable energy carriers also not only reveals the relevance of citizens' movements but also leads to the continuous involvement of civil society in the outline of the future energy system (cf. Morris and Pehnt 2012; SRU 2013). The obvious necessity of interpreting the German energy transition as a socio-technical system is not a countryspecific condition, however. Similar conclusions can be drawn for the analysis of transition processes of energy systems in other countries (e.g. Geels et al. 2020).

However, only a small proportion of societal processes have so far been considered in the techno-economic scenario studies, which dominate political advice. The interplay between civil society, politics, technology, and economy is generally not captured (e.g. IEA 2015; EIA 2013; European Commission 2013; Mander et al. 2008; Spiecker and Weber 2014). A similar, but complementary drawback can be observed in climate scenarios, where techno-economic constraints and the interaction with them are frequently not sufficiently considered (Schweizer and Kriegler 2012).

In an endeavour to improve the integration of socio-technical dynamics in energy scenario research, the presentation and discussion of a scenario approach, which tries to depict the systemic interplay between civil society, politics, economy, and technology in a systematic and comprehensive way, is the overarching aim of this special issue. It addresses this challenge by equipping the traditional energy model analysis with a systematic analysis of the uncertainties and complex interactions of the social, political, economic, and technological contextual factors of the energy system, using an instrument of qualitative system analysis called cross-impact balances (CIB, Weimer-Jehle 2006).

The approach takes into account the long tradition of model-based techno-economic scenarios as well as of societal scenarios. It links both traditions to generate so-called integrated or socio-technical scenarios. The general idea of the approach was put forward in other disciplines, in particular in environmental research and climate change research (Alcamo 2008; Nakicenovic et al. 2000), and was recently improved (Schweizer and Kriegler 2012; Schweizer and O'Neill 2014) by enhancing the qualitative part of scenario construction, using the CIB. While this improvement has been recognised and recommended for climate scenario research and beyond by various scholars (Kemp-Benedict 2012; Lloyd and Schweizer 2014; Carlsen et al. 2017; Guivarch et al. 2017; Elsawah et al. 2020), its potential for application in other research fields has received less attention. This special issue tries to give new impetus at this point and adapts this methodological development to the field of energy scenario research.

The expectation of adopting this approach is not only to satisfy scientific curiosity but also to enhance the quality of the findings with regard to the coherence of techno-economic with societal developments and thus to the robustness of policy advice.

The special issue aims at two goals: on the one hand, the roots and conceptualization of the method of socio-technical scenarios will be analysed. On the other hand, two case studies reveal the flexibility of the approach. The case studies will address the German endeavour towards greenhouse gas mitigation as a regional example. The application of the approach itself is not limited to a specific regional context. 
In its aim to improve the systematic integration of socio-technical context processes in energy scenario research, the special issue puts itself in a wider context of recent broad-based efforts by the scientific scenario community to critically review previous practice, identify flaws, and enhance the application of scenario methodology in environmental and energy research (e.g., Elsawah et al. 2020). The influence of socio-technical dynamics is only one challenge in the field. Another issue is, for instance, how to better deal with complexity and uncertainty in general, as addressed in a recent special issue of Environmental Modelling and Software (Guivarch et al. 2017). This topic is closely connected to the challenge of addressing socio-technical effects, because the uncertainty of societal and social developments is one source of uncertainty for environmental and energy systems, and the systemic interplay between the contextual factors and the feedback from the system to the context is an element of system complexity. In this broader environment, the present special issue intends to complement the Guivarch et al. (2017) special issue, and as a component of the current efforts of the scenario community towards better scenario practice.

\section{Outline}

This special issue did not begin on a green field. It builds on a concept development pursued during the ENERGY-TRANS project ${ }^{1}$ by a group of energy modellers, economists, social scientists, and system researchers which was published several years ago (Weimer-Jehle et al. 2016). However, a concept is one thing, and practical application is another. In this sense, the special issue is a follow-up, shedding light on the question of whether this concept was able to prove itself in practice.

The special issue consists of four articles. The first article is a 'guest article', reporting how the CIB method is used as a storyline generator and storyline evaluator in a related fieldclimate change research - and a reflection about its effects in this field (Schweizer 2020). The core of this article is a message of encouragement and justification for why it seems worth the effort of employing CIB in the field of energy scenario research. The second article prepares the ground for placing the proposed methodology in the context of energy scenario research. It offers a state of the art overview of the current practice of combined storyline-and-modelling exercises in this field and discusses the strengths and challenges of the CIB method as a storyline generator (Weimer-Jehle et al. 2020). Descriptions of two practice applications of integrated scenario building follow. The third article analyses the interplay between societal developments and energy transition in a national energy system (Pregger et al. 2019), while the fourth article analyses issues of carbon leakage in the steel industry (Vögele et al. 2019).

In her contribution, 'Reflections on cross-impact balances, a systematic method constructing global socio-technical scenarios for climate change research,' Vanessa Schweizer builds on her experiences in employing CIB in climate scenario research. She convincingly substantiates that global studies employing CIB for storyline construction can profit with respect to several aspects: Through CIB's combinatorial approach, it can detect unexpected but meaningful storyline variants possibly overlooked by traditional approaches. This, for instance, has led to the recognition of a shared socioeconomic pathways (SSP) domain in integrated assessment modelling, previously considered meaningless by the scientific community. Through its ability to integrate 'soft factors' (such as governance quality) in the analysis, CIB can uncover in

\footnotetext{
${ }^{1}$ www.energy-trans.de
} 
which direction models (e.g. integrated assessment models) should be extended, by demonstrating the critical influence of such factors. Through the capability of CIB to distinguish storylines with respect to their plausibility, it can direct the gaze of decision makers to scenarios, which deserve special attention. Schweizer provides a practical example drawn from her research: A retrospective CIB-based analysis of the IPCC SRES storylines of the year 2000 (IPCC 2000) showed that CIB would have drawn more attention to high emission scenarios (actually the most relevant emission scenarios, as time has proven).

'Socio-technical energy scenarios: state-of-the-art and CIB-based approaches' by WeimerJehle et al. positions the socio-technical scenario approach discussed in this special issue in the wider field of storyline-informed energy modelling. It shows that the interest of the energy scenario community in combined storyline-and-modelling approaches has surged in the wake of the IPCC SRES report (IPCC 2000) in search of a better acknowledgment of societal aspects in energy scenario research. Above all, however, it shows the diversity of intentions, procedures, methods, and interpretations behind the common label. In the second part of their contribution, the authors review and systematize user observations offered in the scholarly literature about the strength and challenges of the CIB method. User comments indicate that, overall, the CIB fulfils the desires of scholarly scenario researchers for a 'more scientific tool for storyline generation'. However, this comes at a price: a CIB-based analysis of the 'societal parameter space' of an energy model requires time resources.

Pregger et al.'s contribution, 'Moving towards socio-technical scenarios of the German energy transition', presents a reference application case for the socio-technical scenario approach. Its core research interest is to compare the openness of the societal future and the openness of the techno-economic future of a national energy system and to pose the question of which type of future society is a match for which type of energy future. Their 'landscape of societies' shows that the case of very high emission energy pathways is associated with 'medium conservative' societies, dynamic enough to mobilize some economic growth but not dynamic enough to modernize energy structures. Least emission pathways are produced either by precarious societies under strong exogenous transition pressure, or by a type of balanced societies combining the strength of various 'pure' society types. Furthermore, the authors demonstrate how to use the socio-technical scenario approach to identify risk and success factors of the energy transition, and provide one fully elaborated example of a sociotechnical energy scenario in the Supplementary Materials of their contribution. However, in one aspect, Pregger et al.'s socio-technical scenario exercise is not a typical application case: With its CIB analysis of 39 storyline descriptors, it is particularly comprehensive and demanding. Most CIB analyses use a considerably lower number of storyline descriptors.

In 'Socio-technical scenarios for energy-intensive industries: the future of steel production in Germany,' Vögele et al. show that the application field of the approach goes beyond classical energy scenario model analysis, yet is related to energy and climate issues. They analyse a carbon leakage problem, which may occur if less energy efficient, but less costly steel production in other countries, replaces energy-efficient German steel production. They use a cost model to compare production costs in different countries and argue that the parameters of the cost model define a set of uncertain and interacting factors, which require a systematic scenario analysis. By applying the socio-technical scenario approach, they show that the range of plausible differential costs is considerably lower than a purely combinatorial viewpoint would suggest. Another remarkable aspect of this paper, and an inspiration for those global studies combining analysis on different levels, is the multi-level CIB-approach taken by the authors. How to use CIB analysis in a layered system (e.g. global, national, regional) by 
establishing separated cross-impact matrices on each level, and to link them by couplings without producing a CIB matrix too large to handle is an ongoing discussion in the CIB community (Schweizer and Kurniawan 2016; Vögele et al. 2017). In this special issue, Vögele et al. present a multi-level analysis comprising the global, national, and sectoral levels.

In summary, this special issue shows that the presented concept of socio-technical energy scenarios, which is based on the concept of combining societal context analysis using CIB and energy analysis using energy models, has meaningful roots in climate scenario research. We can learn that the concept of socio-technical scenarios is an improvement, or at least an alternative to established approaches in storyline-driven energy modelling. Not only the presented case studies prove its feasibility and productivity but also several other research projects (e.g. Wachsmuth 2015; Ruth et al. 2015; Vögele et al. 2017). However, the process of adapting the concept in practice is still at an early stage. A better clarification of which research questions and in which research designs its strengths can best unfold requires further application experience.

Funding Open Access funding enabled and organized by Projekt DEAL.

Open Access This article is licensed under a Creative Commons Attribution 4.0 International License, which permits use, sharing, adaptation, distribution and reproduction in any medium or format, as long as you give appropriate credit to the original author(s) and the source, provide a link to the Creative Commons licence, and indicate if changes were made. The images or other third party material in this article are included in the article's Creative Commons licence, unless indicated otherwise in a credit line to the material. If material is not included in the article's Creative Commons licence and your intended use is not permitted by statutory regulation or exceeds the permitted use, you will need to obtain permission directly from the copyright holder. To view a copy of this licence, visit http://creativecommons.org/licenses/by/4.0/.

\section{References}

Alcamo J (2008) Environmental futures - the practice of environmental scenario analysis, Amsterdam

Carlsen H, Richard JT, Klein RJT, Wikman-Svahn P (2017) Transparent scenario development. Nat Clim Chang 7:613

EIA - U.S. Energy Information Administration (2013) International energy outlook 2013 - with Projections to 2040. U.S. Energy Information Administration, Washington D.C. http://www.eia.gov/forecasts/ieo/pdf/0484 $\% 282013 \% 29$. pdf $(09.05 .2014)$

Elsawah S, Hamilton S, Jakeman A, Rothman D et al (2020) Scenario processes for socio-environmental analysis: a review of recent efforts and future research needs. Sci Total Environ. https://doi.org/10.1016/j. scitotenv.2020.138393

European Commission (2013) EU energy, transport and GHG emissions - trends to 2050. Reference scenario 2013. Publications Office of the European Union, Luxembourg http://ec.europa. eu/transport/media/publications/doc/trends-to-2050-update-2013.pdf (09.05.2014)

Geels F (2004) From sectoral systems of innovation to socio-technical systems. Insights about dynamics and change from sociology and institutional theory. Res Policy 33:897-920

Geels F, McKeekin A, Pfluger B (2020) Socio-technical scenarios as a methodological tool to explore social and political feasibility in low-carbon transitions: bridging computer models and the multi-level perspective in UK electricity generation (2010-2050). Technol Forecast Soc Chang 151:119258. https://doi.org/10.1016/j. techfore.2018.04.001

Guivarch C, Lempert R, Trutnevyte E (2017) Scenario techniques for energy and environmental research: an overview of recent developments to broaden the capacity to deal with complexity and uncertainty. Environ Model Softw 97:201-210

IEA - International Energy Agency (2015) Energy and climate change. World Energy Outlook Special Report, Paris

IEA - International Energy Agency (2019) World energy outlook 2019. International Energy Agency, Paris 
IPCC - Intergovernmental Panel of Climate Change (2000) Emissions Scenarios. Summary for Policymakers. A special report of IPCC Working Group III. IPCC. https://www.ipcc.ch/site/assets/uploads/2018/03/sres-en. pdf (02.09.2020)

Kemp-Benedict E (2012) Telling better stories: strengthening the story in story and simulation. Environ Res Lett 7:041004

Lloyd EA, Schweizer VJ (2014) Objectivity and a comparison of methodological scenario approaches for climate change research. Synthese 191(10):2049-2088

Mander SL, Bowsa A, Anderson KL et al (2008) The Tyndall decarbonisation scenarios - part I: development of a backcasting methodology with stakeholder participation. Energy Policy 36:3754-3763

Morris C, Pehnt M (2012) Energy Transition - The German Energiewende. Heinrich-Böll Stiftung, Berlin. https://pl.boell.org/sites/default/files/german-energy-transition.pdf (11.09.2020)

Nakicenovic N et al (2000) Special report on emissions scenarios. Cambridge University Press, New York

Pregger T, Naegler T, Weimer-Jehle W, Prehofer S, Hauser W (2019) Moving towards socio-technical scenarios of the German energy transition - lessons learned from integrated energy scenario building. Clim Chang. https://doi.org/10.1007/s10584-019-02598-0

Ruth M, Özgün O, Wachsmuth J, Gößling-Reisemann S (2015) Dynamics of energy transitions under changing socioeconomic, technological and climate conditions in Northwest Germany. Ecol Econ 111:29-47

Schweizer VJ (2020) Reflections on cross-impact balances, a systematic method constructing global sociotechnical scenarios for climate change research. Clim Chang. https://doi.org/10.1007/s10584-019-02615-2

Schweizer VJ, Kriegler E (2012) Improving environmental change research with systematic techniques for qualitative scenarios. Environ Res Lett 7

Schweizer VJ, Kurniawan JH (2016) Systematically linking qualitative elements of scenarios across levels, scales, and sectors. Environ Model Softw 79

Schweizer VJ, O’Neill BC (2014) Systematic construction of global socioeconomic pathways using internally consistent element combinations. Clim Chang 122:431-445

Spiecker S, Weber C (2014) The future of the European electricity system and the impact of fluctuating renewable energy - a scenario analysis. Energy Policy 65:185-197

SRU - German Advisory Council on the Environment (2013) Shaping the electricity market of the future Special Report. German Advisory Council on the Environment, Berlin. http://www.umweltrat. de/SharedDocs/Downloads/EN/02 Special_Reports/2012 2016/2014 02 SG Shaping the Electricity Market_of_the_Future.pdf?_blob=publicationFile (09.05.2014)

Verbong G, Loorbach D (2012) Governing the energy transition. Reality, illusion or necessity. Routledge, New York

Vögele S, Hansen P, Poganietz WR, Prehofer S, Weimer-Jehle W (2017) Scenarios for energy consumption of private households in Germany using a multi-level cross-impact balance approach. Energy 120:937-946

Vögele S, Rübbelke D, Govorukha K, Grajewski M (2019) Socio-technical scenarios for energy-intensive industries: the future of steel production in Germany. Clim Chang. https://doi.org/10.1007/s10584-01902366-0

Wachsmuth J (2015) Cross-sectoral integration in regional adaptation to climate change via participatory scenario development. Clim Chang 132:387-400

WBGU - German Advisory Council on Global Change (2011) World in transition - a social contract for sustainability. Flagship report 2011, Berlin

Weimer-Jehle W (2006) Cross-impact balances: a system-theoretical approach to cross-impact analysis. Technol Forecast Soc Chang 73:334-361

Weimer-Jehle W, Buchgeister J, Hauser W, Kosow H, Naegler T, Poganietz WR, Pregger T, Prehofer S, von Recklinghausen A, Schippl J, Vögele S (2016) Context scenarios and their usage for the construction of socio-technical energy scenarios. Energy 111:956-970. https://doi.org/10.1016/j.energy.2016.05.073

Weimer-Jehle W, Vögele S, Hauser W, Kosow H, Poganietz WR, Prehofer S (2020) Socio-technical energy scenarios: state-of-the-art and CIB-based approaches. Clim Chang. https://doi.org/10.1007/s10584-02002680-y

Publisher's note Springer Nature remains neutral with regard to jurisdictional claims in published maps and institutional affiliations. 